\title{
Study of the Likelihood of Emerging Illegal Dumpsites in High Mountainous Rural Regions of Georgia
}

\author{
NATELA DVALISHVILI ${ }^{1}$, NUGZARI BUACHIDZE ${ }^{2}$
}

${ }^{1}$ Institute of Hydrometeorology of Georgian Technical University, D.Aghmashenebeli ave 150g, Tbilisi 0112, Georgia,e-mail: n.dvalishvili@gtu.ge

${ }^{2}$ Institute of Hydrometeorology of Georgian Technical University, D.Aghmashenebeli ave 150g, Tbilisi 0112 , Georgia,e-mail: emc.buachidze@yahoo.com

Key words: Mountainous Rural Regions, Illegal Dumpsites, Integrated Methodology.

The work was supported by Shota Rustaveli National Science Foundation of Georgia (SENSFG) [grant number: FR-18-718] http://rustaveli.org.ge/

1. Study Area \& Methods

The high mountainous regions of Georgia are characterized by relatively structural weaknesses that contribute to increased likelihood of emerging one of the most widespread problem in Georgia - illegal dumpsites [1]. Within the research, integrated methodology considers determination of the likelihood of emerging illegal dumpsites based on collected statistical data using mathematical formula:

$$
\mathrm{D}=(\mathrm{AC}-(\operatorname{Ln}(\mathrm{L})+\mathrm{Sn}(\mathrm{S})) \mathrm{fq}) / \mathrm{AC} \cdot 100 \%
$$

where: D-percentage of the likelihood of emerging potential illegal dumpsites; A- amount of wastes per capita;C- number of inhabitants;L-capacity of large containers, $\mathrm{kg}$; $\mathrm{n}(\mathrm{L})$ quantity of large containers, item; S- capacity of small containers, $\mathrm{kg}$; $\mathrm{n}(\mathrm{S})$ - quantity of small containers, item; $\mathrm{f}-$ frequency of waste collection (frequency of servicing by the waste truck per week), coefficient from 0 to 1; q-efficiency of waste collection, coefficient from 0 to 1 .

\section{Results \& Discussions}

Obtained statistical data was verified using an unmanned aerial vehicle and field visits and expeditions for the purpose of verification of theoretical data.

Preliminary integrated estimates indicated that the likelihood of illegal dumpsites in high mountainous rural regions of Georgia from 30 to $80 \%$.

\section{Referenses:}

[1] Rural Development Strategy of Georgia 2017-2020, http://enpard.ge/en/wp-content/uploads/2015/05/RuralDevelopment-Strategy-of-Georgia-2017-2020.pdf 